\title{
Space station funding dispute may delay ESA ministers meeting \\ Earth observation programme 'needs tighter coordination'
}

Munich. The European Space Agency (ESA) may have to postpone its next ministerial meeting, scheduled to take place in Toulouse in mid-October, because member states are still unable to decide how to pay for their proposed contribution to the international space station.

But the content of ESA's proposed contribution at least has now become firm. Last week, France told a high level meeting of ESA delegates in Paris that it would withdraw the proposal it made in July to substitute the planned space laboratory, to be built primarily by Germany and Italy, with a French-built crew rescue vehicle (CRV) (see Nature 376, 286; 1995).

The proposal was drawn up in the light of French dissatisfaction with ESA's proposal earlier in the year to drop the CRV from ESA's three-element package. It threatened to delay a final decision on ESA's participation in the space station.

But France's withdrawal, precipitated by ESA's reluctance to change the balance of the programme at short notice, may substitute one headache for another. Because its industrial involvement has been curtailed by the dropping of the CRV, France may now be unwilling to put up the ECU600 million (US\$732 million) that it had previously agreed as its share of the ECU1.42-billion package, which runs from 1996 to 2000.

Italy, which promised ECU300 million, may review its level of participation, because of serious overcommitments in its space activities. In particular, its commitments to the space station through ESA, and through bilateral agreements with the US National Aeronautics and Space Administration, would absorb well over half of the total budget of its space agency ASI up to 2000.

The Italian government's budget plan for 1996 will not be unveiled until the end of this month at the earliest, and it is not known if it will include extra cash to rescue the space programmes. Furthermore, even if extra cash does indeed emerge, it is unlikely to be sufficient. Italian officials are believed to be advising Giorgio Salvini, the research minister, to seek to delay ESA's longplanned ministerial meeting until its own financial situation is clearer, and to renegotiate Italy's level of participation in the space station programme.

Of the three major participants, only Germany is certain to stick to its agreement to provide ECU300 million. Smaller participating countries are to provide ECU150 million. Even without the financial uncertainties of France and Italy, there still remains a shortfall on the total bill of more than ECU100 million, which has so far found no sponsors.

Alison Abbott
Washington. The ambitious US Global Change Research Program (USGCRP), which seeks to use satellite data to develop understanding of terrestrial processes, was taken to task last week by a panel of the National Research Council (NRC).

The panel said in a long-awaited report that the multi-agency effort suffers from a lack of coordination that hampers its scientific output. At the same time, however, it concluded that the programme's research goals were fundamentally sound - a vote of confidence that should help it to survive the congressional budget axe over the next few weeks.

Earlier this year, Robert Walker (Republican, Pennsylvania), the chairman of the House of Representatives Science Committee, asked the NRC to review the USGCRP, which has requested $\$ 1.8$ billion in funding for the next fiscal year, to be distributed among eleven federal agencies that conduct environmental research.

Walker asked the NRC, part of the National Academy of Sciences, to pay particular attention to the National Aeronautics and Space Administration's Mission to Planet Earth (MTPE). This is the largest single element in the global change programme, and has been targeted by Republican lawmakers for deep cuts.

In its report, the NRC affirms that the USGCRP's "fundamental basis is scientifically sound". That finding should boost its credibility with Republican critics, who have accused the Clinton administration of manipulating the programme to support its agenda for setting up international protocols to counter global warming.

According to one panel member, Edward Frieman of the Scripps Institution of Oceanography, the committee found that the "science being done in this programme is of extraordinarily high quality, and is not being politically driven". Frieman says that Walker seemed satisfied with that answer when panel members briefed him last week.

The NRC panel calls for an "adequate and stable level of funding" for global change research. But it also criticizes the programme's lack of interagency coordination, claiming that this leads to inefficiency and missed science opportunities.

Such coordination is supposed to take place in the White House's National Science and Technology Council and its Committee on Environment and Natural Resources, widely touted as a "virtual agency" for government-wide environmental research. But according to the NRC panel, the virtual agency approach is not working.

Part of the problem is excessive focus on individual agency budgets and not enough on presenting a coordinated, multi-agency research plan to which both the Congress and the White House Office of Management and Budget can agree. Frieman, cites a relatively obscure, \$4-million project funded by the DoE to determine the uptake of carbon by the oceans, which Congress has marked for elimination next year. "Here's a critical piece of the science which can vanish overnight because of the vagaries of one

IMAGE
UNAVAILABLE
FOR COPYRIGHT
REASONS

ying high: one of NASA's planned satellites

particular agency's budget," he says. As for NASA's Mission to Planet Earth and its centrepiece, the Earth Observing System (EOS) of environmental satellites, the NRC committee gave another qualified endorsement. The panel called for the first two EOS spacecraft, AM-1 and PM-1, to go ahead as planned, and for a third, Chem-1, to undergo only minor modifications.

After that, however, the programme could be streamlined by taking advantage of new spacecraft technology, as Republican lawmakers and NASA's own study teams have already recommended. Most radical of all, the panel would give the EOS Data and Information System (EOSDIS) a complete overhaul.

The job of producing data for the scientific community would go to a competitively selected federation of government, academic, and industry partners, instead of the handful of government centres now foreseen. Privatizing the data distribution would be "enormously more effective and much cheaper", says Frieman.

Initial reaction to the $\mathrm{NRC}$ report in Congress has been favourable, with both sides of the funding debate claiming that it supports their position. The day before the report came out, the Senate subcommittee that oversees NASA's budget granted nearly the full amount for MTPE - cutting only \$61 million from a $\$ 1.34$ billion request, compared to a $\$ 339$ million cut that has been proposed by the House. Tony Reichhardt 